\title{
Coronary sinus potassium concentration recorded during coronary angioplasty
}

\author{
STUART C WEBB, ANTHONY F RICKARDS, PHILIP A POOLE-WILSON \\ From the Cardiothoracic Institute and National Heart Hospital, Beaumont Street, London
}

SUMMARY Coronary sinus potassium concentration was measured continously in two patients undergoing angioplasty of a significant stenosis of the left anterior descending coronary artery. After each coronary occlusion there was a transient rise in coronary sinus plasma potassium concentration caused by washout of potassium which had accumulated in the extracellular fluid during the short period of ischaemia. There were no significant changes in the surface electrocardiogram and the patients experienced no chest pain. Changes in coronary sinus potassium concentration. provide a sensitive and early indication of myocardial ischaemia in man.

We have developed a catheter-tip electrode for the continuous measurement of plasma potassium concentration. The electrode is structurally similar to that previously used to measure coronary sinus $\mathrm{pH} .{ }^{1}$ The catheter has a potassium sensitive tip in the form of a PVC membrane incorporating valinomycin as the ion selective ligand. ${ }^{2}$ In the two patients reported here, the electrode was used to monitor coronary sinus potassium concentration $\left(\left[\mathrm{K}^{+}\right] \mathrm{cs}\right)$ during percutaneous transluminal angioplasty. ${ }^{3}$

\section{Case reports}

\section{CASE 1}

The first patient was a 48 year old man with a 10 week history of intermittent chest pain after acute anterior myocardial infarction. His medication was timolol $10 \mathrm{mg}$ bd and nifedipine $20 \mathrm{mg}$ tds. A treadmill exercise test was positive; the patient developed chest pain and ST segment depression ( $>1 \mathrm{~mm}$ ) occurred in leads V5 and V6. Coronary angiography showed single vessel disease with a severe stenosis of the left anterior descending coronary artery distal to the origin of a second diagonal branch.

Percutaneous transluminal angioplasty was performed using a Gruntzig balloon catheter (Schneider Medintag G-20-37). At the start of the procedure, a thin-walled Cournand catheter (USCI 8F) was inserted into the right femoral vein and positioned with its tip $2 \mathrm{~cm}$ into the coronary sinus. A potassium

Dr Webb is supported by a British Heart Foundation Fellowship.

Accepted for publication 26 April 1983 electrode was introduced through the lumen of this catheter until the tip protruded a further $2 \mathrm{~cm}$ into the coronary sinus.

Three consecutive balloon inflations were performed with a duration of 20 seconds and at intervals of 80 seconds. The mean gradient across the stenosis fell from $50 \mathrm{mmHg}$ to 46,20 , and $2 \mathrm{mmHg}$, respectively. The patient experienced no chest pain. In lead V5 of the surface electrocardiogram the only change was a slight diminution in $\mathrm{T}$ wave amplitude. No change in $\left[\mathrm{K}^{+}\right]$cs was observed while the balloon was inflated, but a transient rise occurred 4.5 seconds after each arterial occlusion (Fig. 1). A peak rise of $0.3 \mathrm{mmol} / \mathrm{l}$ above the baseline $\left[\mathrm{K}^{+}\right] \mathrm{cs}$ of $4.0 \mathrm{mmol} / \mathrm{l}$ was recorded. At the end of the procedure, angiography showed a distinct improvement in the stenosis and the patient remained symptom free during three months follow up. Repeat treadmill exercise testing was negative.

\section{CASE 2}

The second patient was a 54 year old man with a four year history of classical angina pectoris and a confirmed anterior myocardial infarction one year previously. He was investigated because of a deterioration in his exercise capability. Coronary angiography showed single vessel disease with a severe stenosis in his left anterior descending coronary artery distal to the origin of the septal and diagonal branches.

Percutaneous transluminal angioplasty was performed. The balloon catheter was inflated for $20 \mathrm{sec}-$ onds at intervals varying between 100 and 270 seconds. The mean pressure gradient across the stenosis 


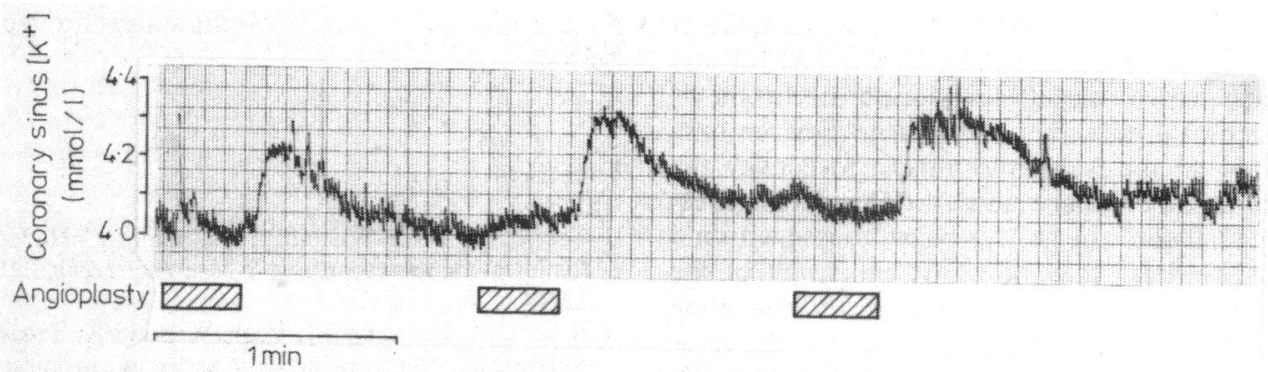

Fig. 1 Continuous coronary sinus potassium recording during three consecutive angioplasty balloon occlusions of the left anterior descending coronary artery (case 1$).\left[\mathrm{K}^{+}\right] \mathrm{cs}$ did not change during occlusion but rose transiently approximately 4 seconds after each balloon deflation.

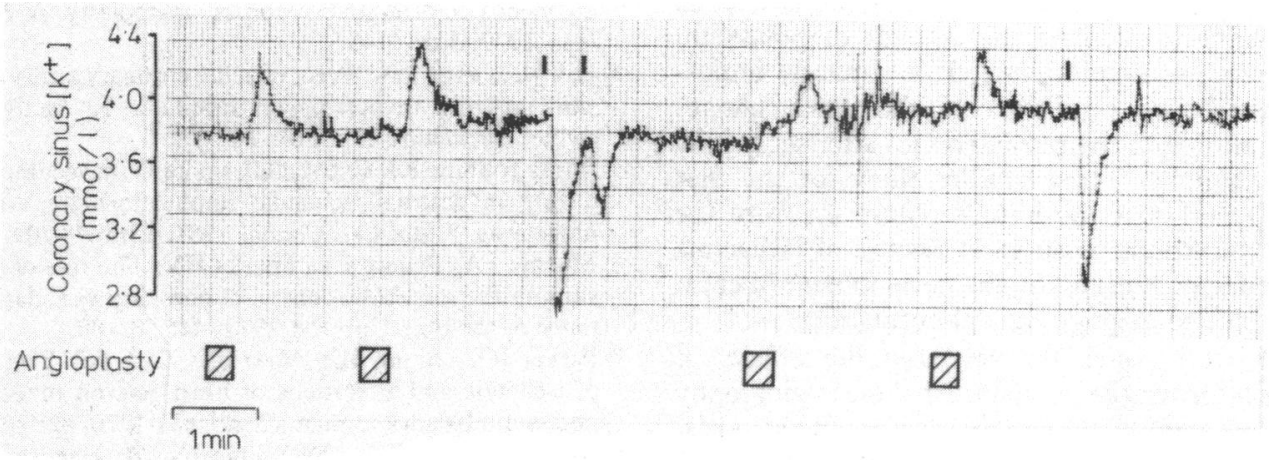

Fig. 2 Continuous coronary sinus potassium recording during four angioplasty balloon occlusions of the left anterior descending coronary artery and three injections of contrast medium into the left coronary artery (I) (case 2). $\left[\mathrm{K}^{+}\right]$cs rose transiently after balloon deflation with a delay of between 6 and 8 seconds. Passage of contrast medium through the coronary sinus caused an abrupt transient fall in $\left[K^{+}\right]$cs.

dropped from $49 \mathrm{mmHg}$ to $21,28,19$, and $17 \mathrm{mmHg}$, respectively. During coronary occlusion there was little change in $\left[\mathrm{K}^{+}\right] \mathrm{cs}$, but after a delay of between 6 and 8 seconds it rose transiently to a maximum of $0.6 \mathrm{mmol} / \mathrm{l}$ above a baseline value of $3.8 \mathrm{mmol} / \mathrm{l}$ (Fig. 2). During coronary angiography there was a brief fall in $\left[\mathrm{K}^{+}\right] \mathrm{cs}$ because of the passage of a bolus of potassium-free contrast medium (Fig. 2). The fall was up to $1 \mathrm{mmol} / \mathrm{l}$. There were no changes in the surface electrocardiogram at any stage during the procedure, and heart rate remained constant. The patient remained symptom free throughout. Angiography after the final arterial dilatation showed no residual stenosis. The patient did not experience any chest pain in the two weeks after angioplasty and a treadmill exercise test was negative.

\section{Discussion}

Animal studies have shown that potassium is lost from the myocardial cell within seconds of the onset of ischaemia. The extracellular potassium rises ${ }^{4} 5$ and an increased potassium concentration can be detected in the coronary sinus. ${ }^{6}$ In man, similar changes have been reported when myocardial ischaemia is induced by atrial pacing. ${ }^{7}$ The use of atrial pacing complicates the interpretation of such studies since an increase in heart rate in the absence of ischaemia causes a loss of potassium from heart muscle. ${ }^{6} 7$

Percutaneous transluminal angioplasty provides a unique opportunity to study the physiological effects of acute coronary occlusion in man. ${ }^{8}$ We have used a catheter-tip electrode which recorded continuously coronary sinus plasma potassium concentration. The system is stable and can detect changes in concentration of $0.05 \mathrm{mmol} / \mathrm{l}$. Results have been expressed as concentration and not activity; the electrode was calibrated in normal saline containing known quantities of potassium.

The recordings obtained from these patients show that though $\left[\mathrm{K}^{+}\right] \mathrm{cs}$ did not change significantly during coronary occlusion, a transient rise occurred when the occlusion was removed. There was no alteration in heart rate and as the steady state myocardial potassium balance is zero, ${ }^{7}$ this rise cannot be attributed to changes in blood flow. It therefore represents washout 
of potassium that has accumulated in the extracellular fluid during the ischaemic period. The lack of any significant change in $\left[\mathrm{K}^{+}\right]$cs during occlusion is explained by the fact that there is no flow or only limited flow to the ischaemic muscle to convey the potassium to the coronary sinus. After reducing pressure in the balloon, the $\left[\mathrm{K}^{+}\right] \mathrm{cs}$ began to rise within 8 seconds. The delay may be partly the result of the time to deflate the balloon and partly the time required for blood to flow from the tissue to the coronary sinus electrode. The maximum rise observed was $0.6 \mathrm{mmol} / \mathrm{h}$ and could easily be detected by this method. It is not possible, without a continuous measurement of regional coronary flow and knowledge of the degree of mixing the blood from non-ischaemic myocardium, to calculate the amount of potassium lost from the ischaemic tissue. It is similarly impossible to ascribe any significance to the minor changes in the amplitude of the rise in $\left[\mathrm{K}^{+}\right] \mathrm{cs}$ after sequential balloon inflations. These studies show for the first time, however, that the loss of potassium from the human myocardium is an early feature of ischaemia and precedes such events as the development of chest pain and electrocardiographic abnormalities.

Existing techniques for assessing the effects of angioplasty during the procedure include angiography and measurement of the gradient across the stenosis. These methods do not indicate the extent to which the apparent reduction of a stenosis is related to the ability to increase the level of myocardial work before the onset of ischaemia. Such information might be obtained by monitoring $\left[\mathrm{K}^{+}\right] \mathrm{cs}$ during atrial pacing before and after angioplasty. This would provide an immediate and physiologically useful measure of the extent to which the procedure had been successful.
We are grateful to Mr R Montgomery for technical assistance.

\section{References}

1 Cobbe SM, Poole-Wilson PA. Catheter tip pH electrodes for intravascular recording. F Med Eng Technol 1980; 4: $122-4$.

2 Band DM, Kratochvil J, Poole-Wilson PA, Treasure T. Relationship between activity and concentration measurements of plasma potassium. Analyst 1978; 103: 24651.

3 Grïntzig AR, Senning A, Siegenthaler WE. Nonoperative dilatation of coronary-artery stenosis. Percutaneous transluminal coronary angioplasty. $N$ Engl f Med 1979; 301: 61-8.

4 Hill JL, Gettes LS. Effect of acute coronary artery occlusion on local myocardial extracellular $\mathrm{K}^{+}$activity in swine. Circulation 1980; 61: 768-78.

5 Weiss J, Shine KI. Extracellular potassium accumulation during myocardial ischemia: implications for arrhythmogenesis. I Mol Cell Cardiol 1981; 13: 699-704.

6 Murray PA, Belloni FL, Sparks HV. The rôle of potassium in the metabolic control of coronary vascular resistance of the dog. Circ Res 1979; 44: 767-80.

7 Parker JO, Chiong MA, West RO, Case RB. The effect of ischemia and alterations of heart rate on myocardial potassium balance in man. Circulation 1970; 42: 205-17.

8 Rothman MT, Baim DS, Simpson JB, Harrison DC. Coronary hemodynamics during percutaneous transluminal coronary angioplasty. Am $\mathcal{F}$ Cardiol 1982; 49: 161522.

Requests for reprints to Professor P A Poole-Wilson, Cardiothoracic Institute, 2 Beaumont Street, London W1N 2DX. 